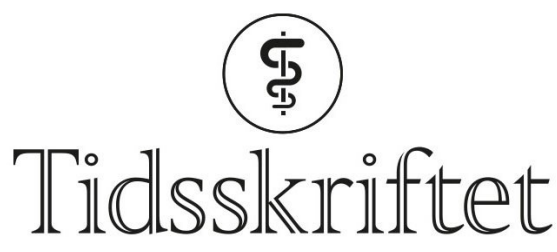

DEN NORSKE LEGEFORENING

\title{
En kvinne i 6o-årene med angst, nedsatt stemningsleie og endret atferd
}

NOE Å LÆRE AV

MARTIN BYSTAD

E-post: martin.k.bystad@uit.no

Alderspsykiatrisk avdeling

Universitetssykehuset Nord-Norge

og

Institutt for psykologi

Universitetet i Troms $\varnothing$

Martin Bystad (f. 1982) er psykologspesialist ved Alderspsykiatrisk avdeling, Universitetssykehuset i

Nord-Norge og ph.d.-stipendiat ved Universitetet i Troms $\varnothing$.

Forfatter har fylt ut ICMJE-skjemaet og oppgir ingen interessekonflikter.

\section{HILDE HOLME}

Alderspsykiatrisk avdeling

Universitetssykehuset Nord-Norge

Hilde Holme (f. 1967) er psykolog ved Alderspsykiatrisk avdeling, Universitetssykehuset i Nord-Norge.

Hun er under spesialisering i klinisk voksen- og eldrepsykologi.

Forfatter har fylt ut ICMJE-skjemaet og oppgir ingen interessekonflikter.

\section{OLE KRISTIAN GRøNLI}

Alderspsykiatrisk avdeling

Universitetssykehuset Nord-Norge

og

Institutt for klinisk medisin

Universitetet i Troms $\emptyset$

Ole Kristian Grønli (f. 1963) er spesialist i psykiatri og ph.d. Han er seksjonsoverlege ved

Alderspsykiatrisk avdeling, Universitetssykehuset i Nord-Norge og førsteamanuensis ved

Universitetet i Tromsø.

Forfatter har fylt ut ICMJE-skjemaet og oppgir ingen interessekonflikter.

En kvinne i 6o-årene hadde symptomer forenlig med frontotemporal demens og kom på sykehjem. Ved fornyet vurdering ett år senere viste det seg at årsaken til hennes symptomer var en annen.

Kvinnen ble frivillig innlagt i akuttpsykiatrisk avdeling etter intoksikasjon med benzodiazepiner, noe som var gjort i suicidal hensikt. Hun hadde hatt vedvarende angst og depresjon de siste fem årene og var blitt fulgt opp av fastlegen. Hun forklarte suicidfors $ø$ ket ut fra at hun i etterkant av time hos fastlegen følte at hun ikke ble forstått, og hun opplevde ikke noe håp om bedring av sine plager. 
Ved innleggelsen uttrykte hun bekymring over sine psykiske symptomer, skam over suicidforsøket og vansker med å forstå at hun hadde gjort dette. Det fremkom ikke opplysninger om depressive episoder tidligere i livet, men det var bipolar lidelse i slekten. Før innleggelse hadde medikamentell behandling med antidepressiver i form av escitalopram og mianserin vært forsøkt uten effekt. Pasienten hadde også over lengre tid brukt benzodiazepiner (oxazepam) på grunn av økende angst og søvnplager. Utover dette var pasienten frisk somatisk, og hun var fortsatt $i$ arbeid.

Det ble vurdert at pasienten hadde en moderat depresjon, i tillegg til at hun hadde utviklet avhengighet av benzodiazepiner.

Det ble startet behandling med venlafaxin $75 \mathrm{mg}$ mot depresjon, og oxazepam ble redusert til $10 \mathrm{mg}$ x 2 og delvis erstattet av klorprotiksen 15-30 mg x 2, og zopiklon 7,5 mg x 1 mot søvnvansker. Hun ble fulgt opp av akutteam etter utskrivning. Lege ved akuttpost samarbeidet med fastlegen om den medikamentelle behandlingen, og hun ble henvist til voksenpsykiatrisk poliklinikk.

Noen uker senere ble hun innlagt for annen gang på grunn av depresjon, angst og søvnplager. Tilstanden fremsto som forverret. Hun var ikke tilbake i arbeid. Ytterligere noen uker etter utskrivning ble hun innlagt for tredje gang. Symptombildet bar preg av $\emptyset \mathrm{kt}$ angst, skjelvinger, store bekymringer og skam over suicidforsøket og sine psykiske plager, unngåelsesatferd og mer isolasjon. Hun hadde økt inntaket av oxazepam til 70-80 mg/døgn. Ved innleggelsene ble venlafaxin gradvis økt til $225 \mathrm{mg}$, og oxazepam ble igjen gradvis redusert. Mianserin ble seponert og erstattet med olanzapin $10 \mathrm{mg}$ (kveld). Hun brukte i tillegg oxazepam $10 \mathrm{mg}$ inntil x 2, klorprotiksen 15-30 mg inntil x 3 og zopiklon 7,5 mg som behovsmedikasjon ved utskrivning. Både andre og tredje innleggelse var frivillige.

Diagnosen depresjon ble opprettholdt. Det ble også satt en tentativ uspesifikk angstdiagnose. Etter utskrivning ønsket hun ikke oppfølging fra psykiatritjenesten, men hun ble fulgt opp av fastlegen og voksenpsykiatrisk poliklinikk. Det ble anbefalt gradvis seponering av oxazepam.

Ved fjerde innleggelse tre måneder senere hadde pasientens tilstand forverret seg. Det var problemer med hygiene, ernæring og sosial kontakt. Pasienten møtte ikke til polikliniske timer. Hun hadde autoseponert antidepressiver og olanzapin og brukt stadig mer oxazepam, med døgndoser på 6o-8o mg tross bivirkninger som økt angst og skjelvinger. Symptombildet bar også preg av tiltaksløshet, likegyldighet, konsentrasjonsvansker og tremor og rykninger i kroppen. Derfor ble det foretatt en langsom nedtrapping og seponering av oxazepam under en ti ukers innleggelse, og det ble startet opp behandling med propranolol $80 \mathrm{mg} \mathrm{x} 1$ mot tremor, mirtazapin $30 \mathrm{mg}$ i kombinasjon med flupentiksol $1 \mathrm{mg} \times 3$ mot angst og depresjon, i tillegg til zopiklon 7,5 mg.

Resultatet av nevrologisk undersøkelse var usikkert på grunn av pasientens tremor, og det ble utført CT caput som var uten anmerkninger. Under innleggelsen fremsto pasienten rigid og med mye unnvikelsesatferd. Hun hadde vansker med å ta del i egen behandling tross mye motiveringsarbeid. Dette bedret seg noe under innleggelsen. Ved utskrivning til hjemmet fremsto hun bedre av angstplagene og med noe bedre innsikt i egen situasjon. Hun uttrykte selv usikkerhet til om hun ville klare seg hjemme og uten oxazepam. Det ble etablert oppfølging fra kommunal psykiatritjeneste tre ganger ukentlig.

Diagnosen moderat depresjon ble opprettholdt ved utskrivning, i tillegg til uspesifisert angstlidelse som tentativ diagnose. Det ble vurdert at pasienten hadde nedsatt sykdomsinnsikt.

Tre uker senere ble pasienten for femte gang innlagt, denne gang til tvungen psykiatrisk observasjon på grunn av mistanke om psykose. Det var tilkommet ytterligere vekttap, og hun var ukritisk, avvisende, bagatelliserende, irritabel og motorisk urolig. Under innleggelse fremkom ingen psykotiske symptomer. Somatisk undersøkelse var uten anmerkninger. Det ble stilt spørsmål om mulig demensutvikling. Kognitive screeningtester ble gjennomført. På Mini Mental Status-test (MMS) skåret hun 25/30 og på klokketest 5/5. På 
ordflyt (Animal Naming Test) klarte hun kun ni ord på ett minutt.

Det ble startet opp behandling med bupropion $300 \mathrm{mg}$ mot depresjon og fortsatt behandling med propranolol $80 \mathrm{mg}$. Flupentiksol og mirtazapin ble seponert. Hun viste noe mer initiativ under innleggelsen. Etter utskrivning til hjemmet hadde hun fortsatt kontakt med psykiatritjeneste og tett oppfølging fra fastlegen.

Demens ble vurdert som en mulig differensialdiagnose. Men pasientens alder, resultater på de kognitive screeningtestene, komparentopplysninger og det kliniske bildet ga ikke nok støtte til en demensdiagnose. Hun ble igjen skrevet ut med depresjonsdiagnose, med anbefaling om kognitiv retesting etter seks måneder.

Ett år etter den femte innleggelsen ble pasienten igjen innlagt til tvungen psykiatrisk observasjon med mistanke om depresjon og demensutvikling. Pasientens tilstand hadde gradvis forverret seg med betydelig vekttap og selvneglisjering, funksjonssvikt og sosial isolasjon. Psykiatritjenesten uttrykte stor bekymring for pasientens helsetilstand. Pasienten selv stilte seg uforstående til at omgivelsene var bekymret. Under innleggelsen fremsto hun initiativløs og avvisende. Hun var verbalt kortfattet, mimikkfattig og psykomotorisk treg. MMS-test og klokketest viste samme resultat som ett år før. Det ble ikke gjort medisinendringer. Hun ble nå utskrevet med diagnosen mild depresjon.

Det ble på nytt stilt spørsmål om demensutvikling, men uten noen konklusjon. Heller ikke denne gangen var det kliniske bildet entydig. Det ble avtalt tettere oppfølging fra psykiatritjenesten og fastlegen..

Ni måneder etter den ovennevnte innleggelsen ble pasienten igjen henvist av fastlegen på grunn av uttalt initiativløshet, selvneglisjering og underernæring. Hun hadde igjen autoseponert medisiner. Psykiatritjenesten hadde store problemer med å få hjulpet pasienten. Både psykiatritjenesten og fastlegen mente at pasientens sykdomsbilde var lite forenlig med depresjon. Denne gangen ble hun innlagt til tvungen psykiatrisk observasjon ved alderspsykiatrisk seksjon.

Under innleggelsen var pasienten preget av uttalt initiativløshet, som ble tolket som apati, betydelig selvneglisjering og likegyldighet. Videre var det kliniske bildet fortsatt preget av avvisning, men det fremkom ingen klare tegn på tristhet eller psykotiske symptomer. Pasienten pratet svært lite, men kunne svare kort på spørsmål. Mange av svarene var preget av gjentagelser av typen «vet ikke», «det går bra» og «det feiler meg ingenting».

Pasienten ble tverrfaglig vurdert under innleggelsen ved alderspsykiatrisk seksjon. Hun hadde ikke respondert på medikamentell behandling av depresjon. Rutinemessig unders $\varnothing$ kelse med blodprøver og nevrologisk status viste ingen tegn til sykdommer/skader i nervesystemet eller andre somatiske sykdommer, som kunne forklare pasientens alvorlige apati. Sykehistorien var lite forenlig med Alzheimers sykdom eller vaskulær demens.

Pårørende fortalte at pasienten hadde endret seg vesentlig de siste årene. Hun hadde gått fra å være en yrkesaktiv og velorganisert person med kontakt med familien til å bli gradvis $\emptyset$ kende apatisk. Skjemaet Frontal behavior inventory ble fylt ut av pårørende. I dette skjemaet kartlegger man endringer i personlighet og atferd, og det brukes som et hjelpemiddel for å diagnostisere frontotemporal demens.

Pasienten fikk en skår på 34, som er høyere enn beslutningsgrensen $(>27)$ ved frontotemporal demens. Dette tydet på at det hadde vært en betydelig endring i pasientens personlighet og sosiale atferd, forenlig med frontotemporal demens. Det ble fylt ut pårørendeskjema (informant questionnaire of cognitive decline in the elderly) med spørsmål om endring i hukommelse/orientering. Her ble det rapportert en gjennomsnittlig skår på 3,o (cut-off ved mistanke om Alzheimers demens er en gjennomsnittlig skår på > 3,5). Kognitiv eller nevropsykologisk testing av pasienten ble ikke gjennomført, da pasienten ikke $\emptyset$ nsket en slik utredning. CT caput var normal. Det ble gjort en SPECT-unders $ø$ kelse (single photon emission computerized tomography), som viste hypoperfusjon frontalt, temporalt og parietalt. Det ble antydet at dette kunne være forenlig med (tidlig) demens.

Observasjon i miljøet og samtaler med pasienten ga fortsatt ingen holdepunkter for tristhet 
eller nedsatt stemningsleie. Apati dominerte det kliniske bildet. Både overleger, psykologspesialist og psykiatriske sykepleiere vurderte det som lite sannsynlig at pasienten hadde en depressiv episode.

Ved depresjon er grunnsymptomene tap av energi, tristhet og nedsatt stemningsleie, $\mathrm{i}$ tillegg til manglende evne til å føle glede. Pessimisme, angst, selvmordstanker, søvnvansker og initiativløshet er øvrige depressive symptomer. For å kunne klassifisere en tilstand som depresjon må to av grunnsymptomene, samt minst to av de øvrige depressive symptomene, være til stede i mer enn to uker. Pasientens symptomer passet ikke overens med ICD-10kriteriene for depressiv episode (F32.o-F32.3) eller kriteriene for diagnosen «Andre spesifiserte depressive episoder» $\left(\mathrm{F}_{3} 8.2\right)$.

Ved frontotemporal demens er det imidlertid vanlig med både apati, passivitet, initiativløshet, redusert taleflyt, selvneglisjering og emosjonell avflatning. Dette gjelder spesielt ved en pseudodepressiv variant av tilstanden (1). Disse symptomene var uttalte hos vår pasient.

Flere vurderinger ble gjort. Pasientens langsomme endring av atferd og personlighet og hennes langvarige apati, sammen med funnene ved SPECT-undersøkelsen og det øvrige kliniske bildet, trakk i retning av at pasienten hadde en hjerneorganisk sykdom. Pasientens tilstand var mest forenlig med en pseudodepressiv variant av frontotemporal demens. Derfor ble diagnosen frontotemporal demens satt, som i ICD-10 er rubrisert under «Personlighetsforstyrrelser og atferdsforstyrrelser som skyldes sykdom, skade og dysfunksjon i hjernen» (Fo7.o). Bruk av legemidler mot demens er ikke aktuelt for pasienter med denne tilstanden.

Behandling med bupropion $300 \mathrm{mg}$ ble videreført. Hun ble skrevet ut fra alderspsykiatrisk avdeling, og kommunal hjemmetjeneste tok over det videre ansvaret, bl.a. med å assistere pasienten ved alle måltider og ved stell.

Ni måneder senere ble pasienten tildelt plass på sykehjem fordi hun hadde behov for et høyere omsorgsnivå. Etter å ha vært på sykehjem i ni måneder ble pasienten henvist til alderspsykiatrisk poliklinikk av sykehjemslegen. Sykehjemmet hadde etter hvert stilt spørsmål ved om diagnosen frontotemporal demens var riktig. Det fremkom at pasienten var blitt gradvis mindre apatisk etter innleggelse på sykehjem. Hun fant seg godt til rette og ivaretok etter hvert personlig hygiene og ble normalvektig. Personalet opplevde henne som rolig og hyggelig, men tok hensyn til at hun lett kunne føle seg overkjørt og "dirigert». Hun var med på turer, hadde egne nøkler og fri utgang. Bupropion (antidepressiver) som ble startet opp ved alderspsykiatrisk seksjon, var blitt seponert etter tre måneder på sykehjemmet.

Psykolog ved alderspsykiatrisk poliklinikk gjorde en nevropsykologisk utredning, der det ikke ble funnet noen avvik. Pasientens hukommelse, språk og visuospatiale funksjon (romfølelse), logiske/abstrakte resonnering og eksekutive funksjoner (dvs. evnen til å planlegge, regulere og iverksette sammensatte kognitive operasjoner) var helt intakte. Pasienten hadde begynt å ta vare på seg selv, fått bedre taleflyt og var ikke lenger preget av apati. Hun hadde ikke symptomer på angst eller depresjon.

Etter en grundig vurdering av pasienten ble det konkludert med at hun ikke viste noen atferd som var forenlig med frontotemporal demens. Som følge av hennes gradvise bedring ble hun skrevet ut fra sykehjemmet og flyttet tilbake til sitt eget hjem.

Hun antok selv at hennes plager var forårsaket av avhengighet av oxazepam, dog hadde pasienten vært trappet ut av oxazepam tidlig i sykdomsperioden. Pasienten var kritisk til behandlingen i psykisk helsevern. Utredningen hadde totalt tatt 3,5 år. Det var fortsatt stort sprik mellom egen sykdomsopplevelse og sykehistorie fra komparenter og journal. Hun hadde selv en følelse av å ha blitt nedvurdert. Pasienten var likevel enig i at hun hadde hatt det svært vanskelig og forsto at pårørende var blitt alvorlig bekymret for hennes tilstand. Diagnosen frontotemporal demens ble slettet. Det ble konkludert med at pasienten hadde hatt en langvarig atypisk depresjon. Pasienten ønsket ikke tett oppfølging fra psykolog etter 
utskrivningen fra sykehjem, men heller at fastlegen skulle følge opp videre. Vi avtalte å holde behandlingskontakten åpen, slik at hun kunne ta kontakt ved behov. Ved siste kontakt med pasienten ca. ti måneder etter utskrivning fra sykehjemmet går det fortsatt fint med henne. Hun har ikke depressive plager og har ikke behov for hjemmetjeneste.

\section{Diskusjon}

I Helsedirektoratets veileder for utredning og behandling av depresjon er atypisk depresjon beskrevet slik: «Atypisk depresjon kjennetegnes ved nedstemthet, mens evnen til å reagere følelsesmessig på oppmuntring og stimulering (reaktivitet) er beholdt. Personen er typisk overfølsom for avvisning og kritikk, og kan preges av økt søvnlengde, vektøkning, sterkt nedsatt energi og døgnvariasjon der en kjenner seg dårligst om ettermiddag og kveld» (2).

Heller ikke denne beskrivelsen passet helt for vår pasient, ettersom tristhet/ nedstemthet var fraværende. Derimot var langvarig apati og en rapportert gradvis endring i atferd og personlighet sentralt. Apati er mindre vanlig ved depresjon, men derimot utbredt ved hjerneorganiske sykdommer (3). Pasientens gradvise endring, uttalte apati, reduserte taleflyt, tap av innsikt, men manglende tristhet, gjorde det rimelig å mistenke at vår pasient kunne ha en hjerneorganisk sykdom, herunder frontotemporal demens.

Det er likevel viktig å presisere at manglende opplevelse av tristhet/nedstemthet kan forekomme med depresjon hos eldre, selv om det er uvanlig (4). Det er begrenset litteratur på dette, men generelt er atypisk depresjon vanligere hos eldre enn hos yngre personer (5). Sammenlignet med yngre har deprimerte eldre ofte mer initiativløshet og mindre tristhet/nedstemthet (5).

Vår pasient var underernært. Underernæring kan redusere kognitiv funksjon og medføre apati (6), men pasienten hadde ikke underernæring av en slik grad at den kunne forklare symptombildet.

I en tidligere kasuistikk i Tidsskriftet beskrives en 70-årig kvinne med frontotemporal demens (7). Forfatter anfører at det innen alderspsykiatrien kan være vanskelig å stille rett diagnose og viser til at enkelte pasienter feilaktig kan få en depresjonsdiagnose når det egentlig foreligger en frontotemporal demens. Det er generelt også vår erfaring, men i vår kasuistikk var det altså motsatt problematikk, det vil si at pasienten feilaktig ble oppfattet å ha demensdiagnose.

Frontotemporal demens er en sykdom som lett kan bli oversett, og som det kan være vanskelig å diagnostisere (8). Symptomene som observeres ved tilstanden, mistolkes ofte feilaktig som depresjon, utbrenthet, angst eller overgangsalder (9).

En norsk studie av Rosness og medarbeidere viste at to av tre med frontotemporal demens ble feildiagnostisert ved førstegangsmøte med lege (10). De viste også at det gjennomsnittlig tok 59,2 måneder fra de første symptomene ble rapportert til diagnosen ble stilt. Hos personer under 65 år er tilstanden imidlertid den nest vanligste formen for demens, etter Alzheimers demens (11). Frontotemporal demens rammer i hovedsak personer i alderen 45-65 år (1).

Tilstanden kan manifestere seg litt ulikt. Hos noen er det overaktivitet, bortfall av hemninger og hyperoralitet (uhemmet spising og drikking) som dominerer bildet (1). For andre pasienter kan alvorlig apati, selvneglisjering og mer passiv atferd være mest fremtredende (1). Apati er et svært vanlig tegn på frontotemporal demens i en tidlig fase. Ved depresjon eller angst sees sjelden bekymringsløshet eller språkforstyrrelse (12). Hos vår pasient var det antatt at det var en mer pseudodepressiv variant av frontotemporal demens som var årsaken til pasientens symptomer. Det er antydet at en slik form av tilstanden skyldes degenerasjon av venstre frontallapp (13).

Bildediagnostikk ved SPECT-undersøkelse viste hypoperfusjon, som trakk i retning av hjerneorganisk patologi hos vår pasient. Hypoperfusjon er typisk ved frontotemporal demens. Ved SPECT-undersøkelser er det funnet en sensitivitet på 90\% og spesifisitet på $74 \%$ 
ved frontotemporal demens (14). Det er derfor rimelig at SPECT-undersøkelse anvendes som et ledd i en diagnostisk vurdering. Det er imidlertid viktig å understreke at SPECT-

undersøkelse også kan vise hypoperfusjon ved depresjon (15). Hypoperfusjon ved depresjon gir dårligere behandlingsrespons ved bruk av antidepressive legemidler (15).

Denne sykehistorien tydeliggjør utfordringene ved diagnostikk av frontotemporal demens. Den viser også betydningen av å vurdere atypisk depresjon som en viktig differensialdiagnose. Depresjon med uttalt apati og fravær av tristhet er altså mulig - selv om det er sjeldent. Det er utvilsomt behov for flere diagnostiske hjelpemidler, for eksempel kartleggingsverktøy og kognitive tester, ved utredning av både atypisk depresjon og frontotemporal demens.

\section{LITTERATUR:}

1. Skjerve A, Brenne L. Frontotemporal demens - kjennetegn, diagnostikk og behandlingstiltak. Tidsskrift for Norsk Psykologforening 2002;39:1 - 8 .

2. Helsedirektoratet. Voksne med depresjon. Nasjonal retningslinje for diagnostisering og behandling av voksne med depresjon i primær- og spesialisthelsetjenesten. IS-1561. 2009.

https://helsedirektoratet.no/retningslinjer/nasjonal-retningslinje-for-diagnostisering-og-behandlingav-voksne-med-depresjon-i-primer-og-spesialisthelsetjenesten (5.12.2017).

3. Levy ML, Cummings JL, Fairbanks LA et al. Apathy is not depression. J Neuropsychiatry Clin Neurosci 1998; 10:314 - 9. [PubMed][CrossRef]

4. Gallo JJ, Rabins PV, Anthony JC. Sadness in older persons: 13-year follow-up of a community sample in Baltimore, Maryland. Psychol Med 1999; 29:341 - 50. [PubMed][CrossRef]

5. Engedal K. Alderspsykiatri i praksis. Oslo: Aldring og Helse, 2008.

6. Mowé M. Behandling av underernæring hos eldre pasienter. Tidsskr Nor Lægeforen 2006; 126: 181 - 2. [PubMed]

7. Holm M. 70-årig kvinne med depressive symptomer og personlighetsendring. Tidsskr Nor Lægeforen 2006; 126: 181-3. [PubMed]

8. Hallam BJ, Silverberg ND, Lamarre AK et al. Clinical presentation of prodromal frontotemporal dementia. Am J Alzheimers Dis Other Demen 2007; 22: 456 - 67. [PubMed][CrossRef]

9. Haugen PK. Demens før 65 år. Oslo: Aldring og Helse, 2012.

10. Rosness TA, Haugen PK, Passant U et al. Frontotemporal dementia: a clinically complex diagnosis. Int J Geriatr Psychiatry 2008; 23: 837 - 42. [PubMed][CrossRef]

11. Rosness TA, Haugen PK, Engedal K. Når demens rammer unge. Tidsskr Nor Legeforen 2011; 131: 1194 7. [PubMed][CrossRef]

12. Rosness TA, Engedal K, Chemali Z. Frontotemporal dementia: an updated clinician's guide. J Geriatr Psychiatry Neurol 2016; 29:271 - 80. [PubMed][CrossRef]

13. Mychack P, Kramer JH, Boone KB et al. The influence of right frontotemporal dysfunction on social behavior in frontotemporal dementia. Neurology 2001; 56 (suppl 4): S11 - 5. [PubMed][CrossRef]

14. Mendez MF, Shapira JS, McMurtray A et al. Accuracy of the clinical evaluation for frontotemporal dementia. Arch Neurol 2007; 64: 830 - 5. [PubMed][CrossRef]

15. Amen DG, Trujillo M, Newberg A et al. Brain SPECT imaging in complex psychiatric cases: an evidence-based, underutilized tool. Open Neuroimaging J 2011; 5: 40 - 8. [PubMed][CrossRef]

Publisert: 5. mars 2018. Tidsskr Nor Legeforen. DOI: 10.4045/tidsskr.17.0314

Mottatt 30.3.2017, første revisjon innsendt 10.9.2017, godkjent 5.12.2017.

(C) Tidsskrift for Den norske legeforening 2020. Lastet ned fra tidsskriftet.no 